\title{
Extended EDAS Method for Fuzzy Multi-criteria Decision-making: An Application to Supplier Selection
}

\author{
M. Keshavarz Ghorabaee, E.K. Zavadskas, M. Amiri, Z. Turskis
}

\author{
Mehdi Keshavarz Ghorabaee \\ Department of Industrial Management, \\ Faculty of Management and Accounting, \\ Allameh Tabataba'i University, \\ Tehran, Iran \\ m.keshavarzv_gh@yahoo.com
}

\section{Edmundas Kazimieras Zavadskas*}

Research Institute of Smart Building Technologies,

Vilnius Gediminas Technical University,

Sauletekio al. 11, LT-10223 Vilnius, Lithuania

*Corresponding author: edmundas.zavadskas@vgtu.lt

\section{Maghsoud Amiri}

Department of Industrial Management, Faculty of Management and Accounting,

Allameh Tabataba'i University,

Tehran, Iran

amiri@atu.ac.ir

\section{Zenonas Turskis}

Research Institute of Smart Building Technologies,

Vilnius Gediminas Technical University,

Sauletekio al. 11, LT-10223 Vilnius, Lithuania

zenonas.turskis@vgtu.lt

\begin{abstract}
:
In the real-world problems, we are likely confronted with some alternatives that need to be evaluated with respect to multiple conflicting criteria. Multi-criteria decision-making (MCDM) refers to making decisions in such a situation. There are many methods and techniques available for solving MCDM problems. The evaluation based on distance from average solution (EDAS) method is an efficient multi-criteria decision-making method. Because the uncertainty is usually an inevitable part of the MCDM problems, fuzzy MCDM methods can be very useful for dealing with the real-world decision-making problems. In this study, we extend the EDAS method to handle the MCDM problems in the fuzzy environment. A case study of supplier selection is used to show the procedure of the proposed method and applicability of it. Also, we perform a sensitivity analysis by using simulated weights for criteria to examine the stability and validity of the results of the proposed method. The results of this study show that the extended fuzzy EDAS method is efficient and has good stability for solving MCDM problems.
\end{abstract}

Keywords: Multi-criteria decision-making, Fuzzy sets, Fuzzy MCDM, EDAS method, Fuzzy EDAS, Supplier selection.

\section{Introduction}

Usually, the real-world decision-making problems are very complex and could not be considered as single-criterion problems. In other words, using only one dimension for the decisionmaking process could lead to an unrealistic decision [7], [9], [10], [33], [34]. To obtain more 
comprehensive models for these problems, we need to involve multiple factors or criteria. Multicriteria decision-making (MCDM) comprises efficient methods and techniques to deal with problems that include more than one criterion in the decision-making process [4], [13] [19], [25], [35].

The information about the real-world problems is usually not known accurately. This uncertainty makes the decision-making process complex and challenging. Fuzzy set theory was proposed by Zadeh [31] to deal with this kind of subjective and imprecise information. This theory is a very efficient modeling tool for the MCDM problems in an uncertain environment. Linguistic terms defined by fuzzy sets are usually used to represent uncertain information in the fuzzy decision-making process [18].

Many researchers have applied and extended fuzzy MCDM methods in real-world problems [5], [26], [27]. Nieto-Morote and Ruz-Vila [20] proposed an MCDM approach based on the fuzzy AHP and linguistic terms to evaluate combined cooling, heat, and power production systems. Cagri Tolga et al. [6] developed a fuzzy MCDM approach based on the analytic network process for retail location selection problem. Sedaghat [23] presented a fuzzy MCDM approach based on AHP, TOPSIS, VIKOR and SAW methods for evaluation of productivity improvement of private banks. Wan and Dong [28] developed a new method for solving the multi-criteria group decisionmaking problems with the trapezoidal intuitionistic fuzzy number and incomplete criteria weight information, and used it for stock selection problem. Stanujkic [24] developed an extended version of ARAS method with interval-valued triangular fuzzy numbers and utilized it for evaluating the performance of websites. Baležentis et al. [3] extended the MULTIMOORA method with intuitionistic fuzzy numbers and applied it for personnel selection problem. Keshavarz Ghorabaee [14] proposed an extended VIKOR method with interval type-2 fuzzy sets and applied it to a problem of evaluation and selection of the industrial robots.

Due to involvement of many factors in evaluation and selection of the suppliers, this problem is usually considered as an MCDM problem [12]. Like many other MCDM problems, supplier selection problem is usually handled in an uncertain environment. Therefore, fuzzy MCDM methods and techniques are very useful to deal with this problem. Many researchers have studied supplier selection problem using fuzzy set theory. Yücenur et al. [30] developed a model for selecting the global supplier using the fuzzy analytic hierarchy process and analytic network process. Baležentis and Baležentis [2] developed an innovative MCDM approach based on MULTIMOORA method and 2-tuple linguistics for supplier evaluation and selection. Pitchipoo et al. [22] proposed a structured and integrated decision-making approach for evaluating suppliers by combining the fuzzy analytic hierarchy process and grey relational analysis (GRA). Keshavarz Ghorabaee et al. [15] extended a multi-criteria group decision-making based on the COPRAS method with type-2 fuzzy sets, and applied it to supplier selection process. Kar [16] developed a hybrid group decision support system for supplier selection using analytic hierarchy process, fuzzy set theory and neural network.

The evaluation based on distance from average solution (EDAS) method was introduced by Keshavarz Ghorabaee et al. [17] for inventory ABC classification. It was presented that the EDAS method has good efficiency and needs fewer computations in comparison with other ABC classification methods. Moreover, the efficiency of the EDAS method as an MCDM method was demonstrated by comparing it with some commonly used methods. The evaluation of alternatives in this method is based on distances of each alternative from the average solution with respect to each criterion. In this study, the EDAS method is extended to deal with the fuzzy MCDM problems. In this paper, these linguistic terms are defined by trapezoidal fuzzy numbers to extend the EDAS method in fuzzy environment. A case study of supplier selection is employed to describe the process and demonstrate the effectiveness of the proposed extended method. We also perform a sensitivity analysis with different sets of simulated criteria weights to represent the validity and stability of the ranking results when the weights of criteria are changed. The 
results of sensitivity analysis show that the proposed fuzzy method is stable in different weights of criteria and has a good efficiency in a fuzzy environment.

The rest of this paper is organized as follows. In Section 2, we summarize some basic concepts and definitions about the fuzzy set theory and arithmetic operation of fuzzy numbers. In Section 3, an extended EDAS method is presented to deal with MCDM problems under fuzzy environment. In Section 4, we use a case study of supplier selection to illustrate the procedure and application of the extended EDAS method. In Section 5, a sensitivity analysis is performed to show the validity and stability of the results of the proposed method. The conclusions are discussed in Section 6.

\section{Basic Concepts and Definitions}

Fuzzy set theory was developed by Zadeh [31] for handling problems in which information is imprecise, vague, and uncertain. The term "fuzzy" is related to the situation that we have not well-defined boundaries of the set of activities or observations. Some of the definitions related to fuzzy sets and fuzzy numbers, which are used in this research to extend the EDAS method, are stated as follows:

Definition 1. A fuzzy subset $\widetilde{A}$ of a universal set $X$ can be defined by its membership function $\mu_{\widetilde{A}}(x)$ as [36]:

$$
\widetilde{A}=\left(x, \mu_{\widetilde{A}}(x)\right) \mid x \in X
$$

where $x \in X$ denotes the elements belonging to the universal set, and $\mu_{\widetilde{A}}(x): X \mapsto[0,1]$.

Definition 2. A fuzzy number is a special case of a convex, normalized fuzzy subset $\left(\sup \mu_{\widetilde{A}}(x)=\right.$ 1) of the real line $\mathbb{R}\left(\mu_{\widetilde{A}}(x): \mathbb{R} \mapsto[0,1]\right)[29]$.

Definition 3. A fuzzy number $\widetilde{A}$ is a trapezoidal fuzzy number (TFN) if its membership function is [21]:

$$
\mu_{\widetilde{A}}(x)= \begin{cases}\left(x-a_{1}\right) /\left(a_{2}-a_{1}\right) & a_{1} \leqslant x \leqslant a_{2} \\ 1 & a_{2} \leqslant x \leqslant a_{3} \\ \left(a_{4}-x\right) /\left(a_{4}-a_{3}\right) & a_{3} \leqslant x \leqslant a_{4} \\ 0 & \text { otherwise }\end{cases}
$$

This fuzzy number can also be defined by a quadruplet $\widetilde{A}=\left(a_{1}, a_{2}, a_{3}, a_{4}\right)$. An example of this type of fuzzy numbers is shown in Figure 1.

Definition 4. A crisp number $k$ can be represented by a trapezoidal fuzzy number $\widetilde{k}=(k, k, k, k)$.

Definition 5. Suppose that $\widetilde{A}=\left(a_{1}, a_{2}, a_{3}, a_{4}\right)$ and $\widetilde{B}=\left(b_{1}, b_{2}, b_{3}, b_{4}\right)$ be two positive trapezoidal fuzzy numbers $\left(a_{1} \geqslant 0\right.$ and $\left.b_{1}>0\right)$ and $k$ is a crisp number. The arithmetic operations with these fuzzy numbers are defined as follows [8]:

- Addition:

$$
\begin{gathered}
\widetilde{A} \oplus \widetilde{B}=\left(a_{1}+b_{1}, a_{2}+b_{2}, a_{3}+b_{3}, a_{4}+b_{4}\right) \\
\widetilde{A}+k=\left(a_{1}+k, a_{2}+k, a_{3}+k, a_{4}+k\right)
\end{gathered}
$$

- Subtraction:

$$
\begin{gathered}
\widetilde{A} \ominus \widetilde{B}=\left(a_{1}-b_{4}, a_{2}-b_{3}, a_{3}-b_{2}, a_{4}-b_{1}\right) \\
\widetilde{A}-k=\left(a_{1}-k, a_{2}-k, a_{3}-k, a_{4}-k\right)
\end{gathered}
$$




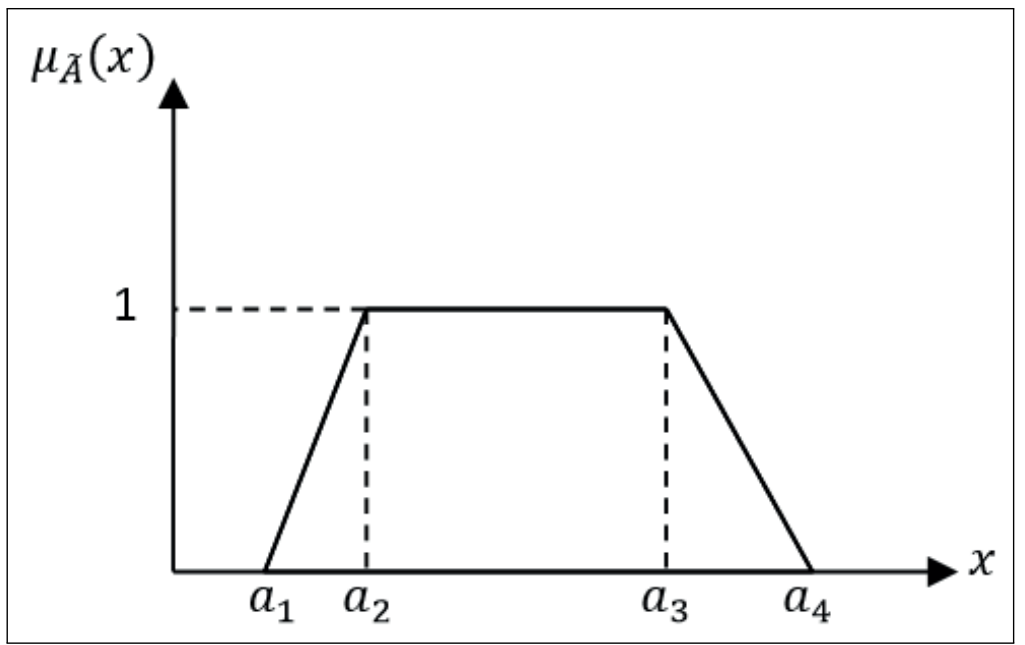

Figure 1: A trapezoidal fuzzy number

- Multiplication:

$$
\begin{gathered}
\widetilde{A} \otimes \widetilde{B}=\left(a_{1} \times b_{1}, a_{2} \times b_{2}, a_{3} \times b_{3}, a_{4} \times b_{4}\right) \\
\widetilde{A} \times k= \begin{cases}\left(a_{1} \times k, a_{2} \times k, a_{3} \times k, a_{4} \times k\right) & \text { if } k \geq 0 \\
\left(a_{4} \times k, a_{3} \times k, a_{2} \times k, a_{1} \times k\right) & \text { if } k<0\end{cases}
\end{gathered}
$$

- Division:

$$
\begin{gathered}
\widetilde{A} \oslash \widetilde{B}=\left(a_{1} / b_{4}, a_{2} / b_{3}, a_{3} / b_{2}, a_{4} / b_{1}\right) \\
\widetilde{A} / k= \begin{cases}\left(a_{1} / k, a_{2} / k, a_{3} / k, a_{4} / k\right) & \text { if } k>0 \\
\left(a_{4} / k, a_{3} / k, a_{2} / k, a_{1} / k\right) & \text { if } k<0\end{cases}
\end{gathered}
$$

Definition 6. Let $\widetilde{A}=\left(a_{1}, a_{2}, a_{3}, a_{4}\right)$ be a trapezoidal fuzzy number. Then, the defuzzified (crisp) value of this fuzzy number can be defined as follows [15]:

$$
\kappa(\widetilde{A})=\frac{1}{3}\left(a_{1}+a_{2}+a_{3}+a_{4}-\frac{a_{3} a_{4}-a_{1} a_{2}}{\left(a_{3}+a_{4}\right)-\left(a_{1}+a_{2}\right)}\right)
$$

Definition 7. Suppose that $\widetilde{A}=\left(a_{1}, a_{2}, a_{3}, a_{4}\right)$ be a trapezoidal fuzzy number. A function, called psi $(\psi)$, is defined in the following to find the maximum between a trapezoidal fuzzy number and zero.

$$
\psi(\widetilde{A})= \begin{cases}\widetilde{A} & \text { if } \kappa(\widetilde{A})>0 \\ \widetilde{0} & \text { if } \kappa(\widetilde{A}) \leqslant 0\end{cases}
$$

where $\widetilde{0}=(0,0,0,0)$.

\section{$3 \quad$ An Extended EDAS Method}

As previously stated, the EDAS method was developed by Keshavarz Ghorabaee et al. [17] for multi-criteria inventory classification. It was also demonstrated that the EDAS method is an efficient method to handle MCDM problems. In this section, an extended version of the EDAS 
method is proposed to deal with multi-criteria group decision-making problems in the fuzzy environment. In this study, the decision-makers express the weights of criteria and the rating of alternatives with respect to each criterion by linguistic terms. These linguistic terms are quantified by positive trapezoidal fuzzy numbers. Therefore, the concepts and arithmetic operations of the trapezoidal fuzzy numbers are utilized for extending the EDAS method. Suppose that we have a set of $n$ alternatives $\left(A=\left\{A_{1}, A_{2}, \ldots, A_{n}\right\}\right)$, a set of $\mathrm{m}$ criteria $\left(C=\left\{c_{1}, c_{2}, \ldots, c_{m}\right\}\right)$ and $k$ decision-makers $\left(D=\left\{D_{1}, D_{2}, \ldots, D_{k}\right\}\right)$. The steps of the extended fuzzy EDAS method are presented as follows:

Step 1: Construct the average decision matrix $(X)$, shown as follows:

$$
\begin{aligned}
X & =\left[\widetilde{x}_{i j}\right]_{n \times m} \\
\widetilde{x}_{i j} & =\frac{1}{k} \bigoplus_{p=1}^{k} \widetilde{x}_{i j}^{p}
\end{aligned}
$$

where $\widetilde{x}_{i j}^{p}$ denotes the performance value of alternative $A_{i}(1 \leq i \leq n)$ with respect to criterion $c_{j}(1 \leq j \leq m)$ assigned by the $p$ th decision-maker $(1 \leq p \leq k)$.

Step 2: Construct the matrix of criteria weights, shown as follows:

$$
\begin{gathered}
W=\left[\widetilde{w}_{j}\right]_{1 \times m} \\
\widetilde{w}_{j}=\frac{1}{k} \bigoplus_{p=1}^{k} \widetilde{w}_{j}^{p}
\end{gathered}
$$

where $\widetilde{w}_{j}^{p}$ denotes the weight of criterion $c_{j}(1 \leq j \leq m)$ assigned by the $p$ th decision-maker $(1 \leq p \leq k)$.

Step 3: Construct the matrix of criteria weights, shown as follows:

$$
\begin{aligned}
A V & =\left[\widetilde{a v}_{j}\right]_{1 \times m} \\
\widetilde{a v}_{j} & =\frac{1}{n} \bigoplus_{i=1}^{n} \widetilde{x}_{i j}
\end{aligned}
$$

The elements of this matrix $\widetilde{a v}_{j}$ represents the average solutions with respect to each criterion. Therefore, the dimension of the matrix is equal to the dimension of criteria weights matrix.

Step 4: Suppose that $B$ is the set of beneficial criteria and $N$ is the set of non-beneficial criteria. In this step the matrices of positive distance from average $(P D A)$ and negative distance from average $(N D A)$ are calculated according to the type of criteria (beneficial and non-beneficial), shown as follows:

$$
\begin{aligned}
& P D A=\left[\widetilde{p d a}_{i j}\right]_{n \times m} \\
& N D A=\left[\widetilde{n d a}_{i j}\right]_{n \times m} \\
& \widetilde{p d a}_{i j}= \begin{cases}\frac{\psi\left(\widetilde{x}_{i j} \ominus \widetilde{a v}_{j}\right)}{\kappa\left(\widetilde{a v}_{j}\right)} & \text { if } j \in B \\
\frac{\psi\left(\widetilde{a v}_{j} \ominus \widetilde{x}_{i j}\right)}{\kappa\left(\widetilde{a v}_{j}\right)} & \text { if } j \in N\end{cases} \\
& \widetilde{n d a}_{i j}= \begin{cases}\frac{\psi\left(\widetilde{a v}_{j} \ominus \widetilde{x}_{i j}\right)}{\kappa\left(\widetilde{a v}_{j}\right)} & \text { if } j \in B \\
\frac{\psi\left(\widetilde{x}_{i j} \ominus \widetilde{a v}_{j}\right)}{\kappa\left(\widetilde{a v}_{j}\right)} & \text { if } j \in N\end{cases}
\end{aligned}
$$


where $\widetilde{p d a}_{i j}$ and $\widetilde{n d a}_{i j}$ denote the positive and negative distance of performance value of $i$ th alternative from the average solution in terms of $j$ th criterion, respectively.

Step 5: Calculate the weighted sum of positive and negative distances for all alternatives, shown as follows:

$$
\begin{aligned}
\widetilde{s p}_{i} & =\bigoplus_{j=1}^{m}\left(\widetilde{w}_{j} \otimes \widetilde{p d a}_{i j}\right) \\
\widetilde{s n}_{i} & =\bigoplus_{j=1}^{m}\left(\widetilde{w}_{j} \otimes \widetilde{n d a} a_{i j}\right)
\end{aligned}
$$

Step 6: The normalize values of $\widetilde{s p}_{i}$ and $\widetilde{s n}_{i}$ for all alternatives are calculated as follows:

$$
\begin{gathered}
\widetilde{n s p}_{i}=\frac{\widetilde{s p}_{i}}{\max _{i}\left(\kappa\left(\widetilde{s p}_{i}\right)\right)} \\
{\widetilde{n s n_{i}}}=1-\frac{\widetilde{s n}_{i}}{\max _{i}\left(\kappa\left(\widetilde{s n}_{i}\right)\right)}
\end{gathered}
$$

Step 7: Calculate the appraisal score $\left(\widetilde{a s}{ }_{i}\right)$ for all alternatives, shown as follows:

$$
\widetilde{a s} i=\frac{1}{2}\left(\widetilde{n s p}_{i} \oplus{\widetilde{n s n_{i}}}\right)
$$

Step 8: Rank the alternatives according to the decreasing values of appraisal scores $\left(\widetilde{a s}_{i}\right)$. In other words, the alternative with the highest appraisal score is the best choice among the candidate alternatives.

\section{Case Study of Supplier Selection}

In this section, we use the proposed fuzzy MCDM method for a real supplier selection case study. The case study is related to a detergent manufacturer. The main product of this company is washing powder. In general, washing powder contains water softeners, bleach, enzymes, surfactants, fragrances, brighteners and many other agents. The company needs to supply the chemical materials of these components from an appropriate supplier for the future of its production. For this aim, the chief executive officer of the company formed a group of five experts from the company's employees. We consider the members of this group as the decision-makers $\left(D M_{1}\right.$ to $\left.D M_{5}\right)$. After a basic assessment performed by this group, five candidates (Supplier 1 to Supplier 5) are remained for further evaluation. These candidates are considered as the alternatives of the MCDM problem $\left(A_{1}\right.$ to $\left.A_{5}\right)$. Six criteria with some sub-criteria are selected by decision-makers for evaluation of suppliers. Figure 2 shows the criteria, sub-criteria and the hierarchical structure of the case study problem.

In this structure, "Total cost" and "Distance" are non-beneficial sub-criteria, and the other sub-criteria are beneficial. The linguistic terms are utilized by decision-makers for evaluation of criteria importance and rating the alternatives on each criterion. These linguistic terms and their corresponding trapezoidal fuzzy numbers are represented in Table 1.

The importance weights of the criteria determined by five decision-makers are shown in Table 2 and the ratings of the alternatives (suppliers) given by these decision-makers under the various criteria are presented in Table 3. The process of using the proposed fuzzy method for this problem is summarized as follows:

Step 1: Based on Tables 1 and 3 and Eqs. (13) and (14), the average decision matrix is constructed. The elements of this matrix can be found in Table 4. 


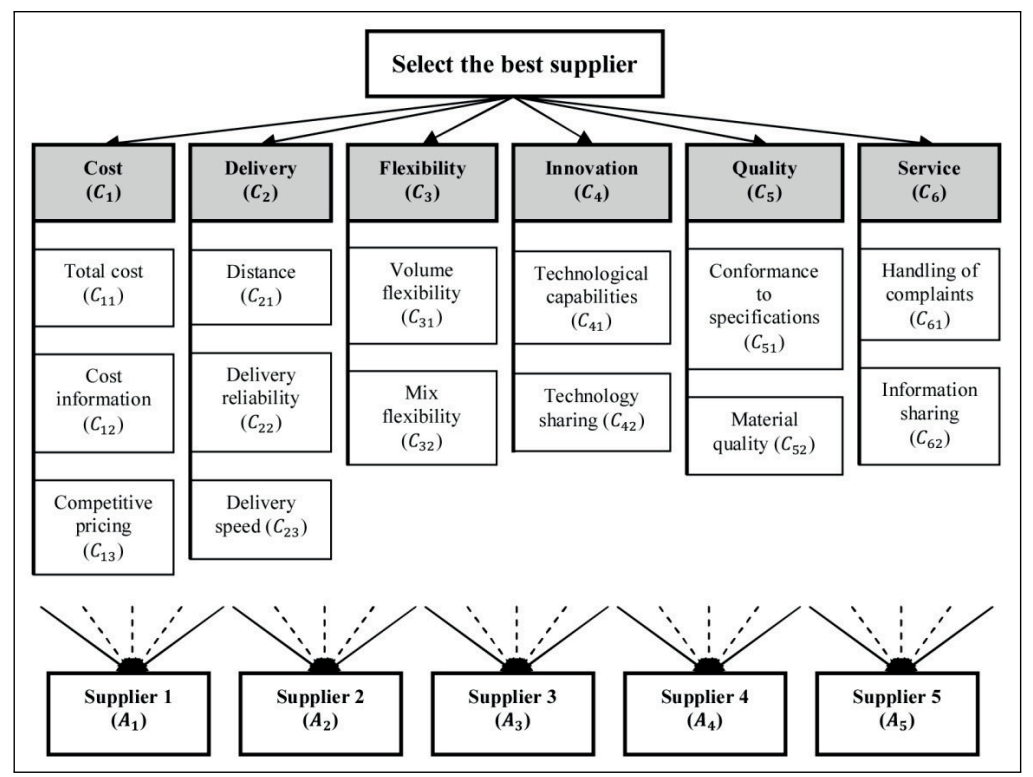

Figure 2: The criteria, sub-criteria and the hierarchical structure of the case study

Table 1: Linguistic terms and their corresponding trapezoidal fuzzy number.

\begin{tabular}{lll}
\hline Terms & TFN for weighting criteria & TFN for rating alternatives \\
\hline Very low (VL) & $(0,0,0.1,0.2)$ & $(0,0,1,2)$ \\
Low (L) & $(0.1,0.2,0.2,0.3)$ & $(1,2,2,3)$ \\
Medium low (ML) & $(0.2,0.3,0.4,0.5)$ & $(2,3,4,5)$ \\
Medium (M) & $(0.4,0.5,0.5,0.6)$ & $(4,5,5,6)$ \\
Medium high (MH) & $(0.5,0.6,0.7,0.8)$ & $(5,6,7,8)$ \\
High (H) & $(0.7,0.8,0.8,0.9)$ & $(7,8,8,9)$ \\
Very high (VH) & $(0.8,0.9,1,1)$ & $(8,9,10,10)$ \\
\hline
\end{tabular}

Steps 2 and 3: Based on Tables 1 and 2 and Eqs. (15) and (16), the average weight of each criterion is calculated (the last column of Table 2), and by using the results of Step 1 and Eqs. (17) and (18) the average solution matrix can be calculated (the last column of Table 4).

Steps 4 to 8: Based on the Table 4 and Eqs. (19) to (27), the positive and negative distances are determined and then we calculate the weighted sum of positive and negative distances $\left(\widetilde{s p}_{i}\right.$ and $\left.\widetilde{s n}_{i}\right)$, the normalized values of them $\left(\left(\widetilde{n s p}_{i}\right.\right.$ and $\left.\left.\widetilde{n s n_{i}}\right)\right)$ and the appraisal scores for all alternatives. Table 5 shows the selected results of these steps. The defuzzified values of appraisal scores are also represented in the last column of this table. According to Table 5, the ranking order of alternatives is $A_{1} \succ A_{5} \succ A_{2} \succ A_{4} \succ A_{3}$. Therefore, $A_{1}$ is the best supplier in our assessment.

\section{Sensitivity Analysis}

To show the stability of the results, the aforementioned example is solved using different sets of criteria (sub-criteria) weights. We simulate 14 sets of weights for the 14 sub-criteria of the example. Figure 3 shows the simulated weights in each set. As can be seen in this figure, one sub-criterion has the highest and one sub-criterion has the lowest weight in each set. Figure 4 shows the ranking of each alternative in each set of criteria (sub-criteria) weights. As can be seen in Figure 4, the ranks of all alternatives are relatively stable in different weights of sub-criteria 
Table 2: The weight of criteria assigned by decision-makers and the matrix of criteria weights

\begin{tabular}{llllllll}
\hline \multicolumn{2}{l}{ Criteria } & $D M_{1}$ & $D M_{2}$ & $D M_{3}$ & $D M_{4}$ & $D M_{5}$ & $W$ \\
\hline$C_{1}$ & $C_{11}$ & $\mathrm{VH}$ & $\mathrm{H}$ & $\mathrm{H}$ & $\mathrm{VH}$ & $\mathrm{VH}$ & $(0.76,0.86,0.92,0.96)$ \\
\cline { 2 - 8 } & $C_{12}$ & $\mathrm{ML}$ & $\mathrm{M}$ & $\mathrm{ML}$ & $\mathrm{L}$ & $\mathrm{L}$ & $(0.2,0.3,0.34,0.44)$ \\
\cline { 2 - 8 } & $C_{13}$ & $\mathrm{M}$ & $\mathrm{MH}$ & $\mathrm{H}$ & $\mathrm{M}$ & $\mathrm{M}$ & $(0.48,0.58,0.6,0.7)$ \\
\hline$C_{2}$ & $C_{21}$ & $\mathrm{VH}$ & $\mathrm{VH}$ & $\mathrm{H}$ & $\mathrm{VH}$ & $\mathrm{MH}$ & $(0.72,0.82,0.9,0.94)$ \\
\cline { 2 - 8 } & $C_{22}$ & $\mathrm{MH}$ & $\mathrm{H}$ & $\mathrm{MH}$ & $\mathrm{MH}$ & $\mathrm{M}$ & $(0.52,0.62,0.68,0.78)$ \\
\cline { 2 - 7 } & $C_{23}$ & $\mathrm{H}$ & $\mathrm{H}$ & $\mathrm{H}$ & $\mathrm{MH}$ & $\mathrm{M}$ & $(0.6,0.7,0.72,0.82)$ \\
\hline$C_{3}$ & $C_{31}$ & $\mathrm{ML}$ & $\mathrm{M}$ & $\mathrm{ML}$ & $\mathrm{M}$ & $\mathrm{M}$ & $(0.32,0.42,0.46,0.56)$ \\
\cline { 2 - 7 } & $C_{32}$ & $\mathrm{~L}$ & $\mathrm{VL}$ & $\mathrm{VL}$ & $\mathrm{L}$ & $\mathrm{ML}$ & $(0.08,0.14,0.2,0.3)$ \\
\hline$C_{4}$ & $C_{41}$ & $\mathrm{VL}$ & $\mathrm{VL}$ & $\mathrm{L}$ & $\mathrm{L}$ & $\mathrm{VL}$ & $(0.04,0.08,0.14,0.24)$ \\
\cline { 2 - 7 } & $C_{42}$ & $\mathrm{VL}$ & $\mathrm{VL}$ & $\mathrm{VL}$ & $\mathrm{VL}$ & $\mathrm{L}$ & $(0.02,0.04,0.12,0.22)$ \\
\hline$C_{5}$ & $C_{51}$ & $\mathrm{H}$ & $\mathrm{MH}$ & $\mathrm{M}$ & $\mathrm{M}$ & $\mathrm{MH}$ & $(0.5,0.6,0.64,0.74)$ \\
\cline { 2 - 7 } & $C_{52}$ & $\mathrm{VH}$ & $\mathrm{VH}$ & $\mathrm{H}$ & $\mathrm{VH}$ & $\mathrm{H}$ & $(0.76,0.86,0.92,0.96)$ \\
\hline$C_{6}$ & $C_{61}$ & $\mathrm{ML}$ & $\mathrm{M}$ & $\mathrm{ML}$ & $\mathrm{L}$ & $\mathrm{ML}$ & $(0.22,0.32,0.38,0.48)$ \\
\cline { 2 - 7 } & $C_{62}$ & $\mathrm{VL}$ & $\mathrm{L}$ & $\mathrm{ML}$ & $\mathrm{ML}$ & $\mathrm{L}$ & $(0.12,0.2,0.26,0.36)$ \\
\hline
\end{tabular}

Table 3: The ratings of the alternatives with respect to each criterion and each decision-maker

\begin{tabular}{|c|c|c|c|c|c|c|c|c|c|c|c|c|c|c|c|}
\hline & & $C_{11}$ & $C_{12}$ & $C_{13}$ & $C_{21}$ & $C_{22}$ & $C_{23}$ & $C_{31}$ & $C_{32}$ & $C_{41}$ & $C_{42}$ & $C_{51}$ & $C_{52}$ & $C_{61}$ & $C_{62}$ \\
\hline \multirow[t]{5}{*}{$D M_{1}$} & $A_{1}$ & VL & $\mathrm{MH}$ & $\mathrm{H}$ & $\mathrm{M}$ & $\mathrm{H}$ & $\mathrm{MH}$ & $\mathrm{M}$ & $\mathrm{H}$ & $\mathrm{MH}$ & ML & $\mathrm{VH}$ & $\mathrm{H}$ & $\mathrm{H}$ & $\mathrm{MH}$ \\
\hline & $A_{2}$ & ML & $\mathrm{H}$ & $\mathrm{H}$ & $\mathrm{MH}$ & $\mathrm{M}$ & $\mathrm{MH}$ & $\mathrm{VH}$ & $\mathrm{MH}$ & $\mathrm{VH}$ & $\mathrm{M}$ & $\mathrm{L}$ & $\mathrm{H}$ & $\mathrm{L}$ & $\mathrm{MH}$ \\
\hline & $A_{3}$ & $\mathrm{H}$ & $\mathrm{M}$ & $\mathrm{L}$ & M & $\mathrm{L}$ & $\mathrm{M}$ & $\mathrm{H}$ & $\mathrm{MH}$ & $\mathrm{L}$ & MH & $\mathrm{L}$ & $\mathrm{L}$ & $\mathrm{M}$ & $\mathrm{L}$ \\
\hline & $A_{4}$ & $\mathrm{VH}$ & ML & $\mathrm{M}$ & $\mathrm{H}$ & $\mathrm{H}$ & VH & $\mathrm{M}$ & $\mathrm{L}$ & $\mathrm{L}$ & $\mathrm{H}$ & $\mathrm{MH}$ & ML & $\mathrm{L}$ & $\mathrm{H}$ \\
\hline & $A_{5}$ & $\mathrm{M}$ & $\mathrm{H}$ & $\mathrm{H}$ & $\mathrm{L}$ & $\mathrm{M}$ & $\mathrm{MH}$ & $\mathrm{VH}$ & $\mathrm{H}$ & $\mathrm{H}$ & M & $\mathrm{MH}$ & $\mathrm{H}$ & $\mathrm{L}$ & MH \\
\hline \multirow[t]{5}{*}{$D M_{2}$} & $A_{1}$ & $\mathrm{~L}$ & $\mathrm{MH}$ & $\mathrm{MH}$ & M & $\mathrm{MH}$ & $\mathrm{H}$ & ML & $\mathrm{MH}$ & M & $\mathrm{L}$ & VH & $\mathrm{H}$ & $\mathrm{H}$ & $\mathrm{H}$ \\
\hline & $A_{2}$ & $\mathrm{M}$ & $\mathrm{H}$ & $\mathrm{M}$ & $\mathrm{M}$ & $\mathrm{M}$ & $\mathrm{MH}$ & $\mathrm{VH}$ & $\mathrm{M}$ & $\mathrm{H}$ & $\mathrm{M}$ & $\mathrm{L}$ & $\mathrm{MH}$ & VL & $\bar{M}$ \\
\hline & $A_{3}$ & $\mathrm{H}$ & $\mathrm{M}$ & ML & ML & $\mathrm{L}$ & $\mathrm{M}$ & $\mathrm{H}$ & $\mathrm{MH}$ & $\mathrm{L}$ & $\mathrm{MH}$ & $\mathrm{L}$ & ML & $\mathrm{M}$ & $\mathrm{L}$ \\
\hline & $A_{4}$ & $\mathrm{VH}$ & $\mathrm{M}$ & $\mathrm{M}$ & $\mathrm{H}$ & $\mathrm{MH}$ & VH & $\mathrm{M}$ & $\mathrm{L}$ & ML & $\mathrm{VH}$ & $\mathrm{M}$ & ML & $\mathrm{L}$ & $\mathrm{H}$ \\
\hline & $A_{5}$ & $\mathrm{M}$ & $\mathrm{H}$ & $\mathrm{H}$ & VL & $\mathrm{M}$ & $\mathrm{MH}$ & $\mathrm{VH}$ & $\mathrm{H}$ & $\mathrm{H}$ & $\mathrm{M}$ & $\mathrm{MH}$ & $\mathrm{H}$ & VL & $\mathrm{MH}$ \\
\hline \multirow[t]{5}{*}{$D M_{3}$} & $A_{1}$ & $\mathrm{~L}$ & $\mathrm{M}$ & $\mathrm{H}$ & ML & $\mathrm{H}$ & $\mathrm{H}$ & ML & $\mathrm{MH}$ & $\mathrm{MH}$ & ML & $\mathrm{H}$ & $\mathrm{MH}$ & $\mathrm{MH}$ & VH \\
\hline & $A_{2}$ & ML & $\mathrm{MH}$ & $\mathrm{MH}$ & $\mathrm{M}$ & $\mathrm{MH}$ & $\mathrm{MH}$ & $\mathrm{H}$ & $\mathrm{MH}$ & $\mathrm{H}$ & $\mathrm{MH}$ & VL & $\mathrm{MH}$ & $\mathrm{L}$ & $\overline{\mathrm{M}}$ \\
\hline & $A_{3}$ & $\mathrm{MH}$ & ML & ML & $\mathrm{M}$ & ML & $\mathrm{MH}$ & $\mathrm{VH}$ & $\mathrm{H}$ & ML & $\mathrm{H}$ & VL & ML & $\mathrm{MH}$ & $\mathrm{L}$ \\
\hline & $A_{4}$ & $\mathrm{H}$ & $\mathrm{L}$ & $\mathrm{MH}$ & $\mathrm{MH}$ & $\mathrm{MH}$ & $\mathrm{H}$ & ML & VL & ML & $\mathrm{VH}$ & $\mathrm{M}$ & $\mathrm{M}$ & VL & $\mathrm{MH}$ \\
\hline & $A_{5}$ & ML & $\mathrm{MH}$ & $\mathrm{H}$ & $\mathrm{L}$ & ML & $\mathrm{H}$ & $\mathrm{H}$ & $\mathrm{MH}$ & $\mathrm{MH}$ & ML & M & $\mathrm{VH}$ & VL & $\mathrm{M}$ \\
\hline \multirow[t]{5}{*}{$D M_{4}$} & $A_{1}$ & VL & $\mathrm{MH}$ & $\mathrm{M}$ & ML & $\mathrm{H}$ & $\mathrm{H}$ & $\mathrm{M}$ & $\mathrm{H}$ & $\mathrm{M}$ & ML & $\mathrm{H}$ & $\mathrm{H}$ & $\mathrm{MH}$ & VH \\
\hline & $A_{2}$ & ML & $\mathrm{H}$ & $\mathrm{M}$ & $\mathrm{M}$ & $\mathrm{MH}$ & $\mathrm{H}$ & $\mathrm{H}$ & $\mathrm{MH}$ & $\mathrm{VH}$ & $\mathrm{M}$ & VL & $\mathrm{H}$ & VL & $\mathrm{MH}$ \\
\hline & $A_{3}$ & $\mathrm{H}$ & ML & ML & ML & ML & $\mathrm{MH}$ & $\mathrm{VH}$ & $\mathrm{H}$ & VL & $\mathrm{H}$ & VL & $\mathrm{L}$ & $\mathrm{M}$ & VL \\
\hline & $A_{4}$ & $\mathrm{H}$ & $\mathrm{L}$ & $\mathrm{MH}$ & $\mathrm{MH}$ & $\mathrm{MH}$ & VH & ML & ML & ML & $\mathrm{VH}$ & $\mathrm{M}$ & ML & VL & $\mathrm{H}$ \\
\hline & $A_{5}$ & $\mathrm{MH}$ & $\mathrm{MH}$ & $\mathrm{MH}$ & ML & ML & $\mathrm{H}$ & $\mathrm{H}$ & $\mathrm{MH}$ & $\mathrm{H}$ & ML & $\mathrm{MH}$ & $\mathrm{H}$ & VL & $\mathrm{M}$ \\
\hline \multirow[t]{5}{*}{$D M_{5}$} & $A_{1}$ & $\mathrm{~L}$ & $\mathrm{H}$ & $\mathrm{MH}$ & $\mathrm{M}$ & $\mathrm{MH}$ & $\mathrm{MH}$ & ML & $\mathrm{MH}$ & $\mathrm{M}$ & $\mathrm{L}$ & VH & $\mathrm{MH}$ & $\mathrm{H}$ & $\mathrm{MH}$ \\
\hline & $A_{2}$ & $\mathrm{M}$ & $\mathrm{H}$ & $\mathrm{M}$ & $\mathrm{MH}$ & $\mathrm{M}$ & $\mathrm{H}$ & $\mathrm{H}$ & $\mathrm{M}$ & $\mathrm{H}$ & $\mathrm{M}$ & $\mathrm{L}$ & $\mathrm{MH}$ & $\mathrm{L}$ & $\mathrm{MH}$ \\
\hline & $A_{3}$ & $\mathrm{MH}$ & $\mathrm{L}$ & $\mathrm{L}$ & $\mathrm{M}$ & ML & $\mathrm{MH}$ & $\mathrm{VH}$ & $\mathrm{M}$ & VL & $\mathrm{MH}$ & VL & $\mathrm{L}$ & $\mathrm{MH}$ & $\mathrm{L}$ \\
\hline & $A_{4}$ & $\mathrm{VH}$ & $\mathrm{L}$ & $\mathrm{M}$ & $\mathrm{MH}$ & $\mathrm{H}$ & $\mathrm{VH}$ & ML & L & $\mathrm{L}$ & $\mathrm{H}$ & $\mathrm{MH}$ & ML & VL & MH \\
\hline & $A_{5}$ & $\mathrm{M}$ & $\mathrm{H}$ & $\mathrm{H}$ & $\mathrm{L}$ & $\mathrm{M}$ & $\mathrm{MH}$ & $\mathrm{VH}$ & $\mathrm{MH}$ & $\mathrm{H}$ & $\mathrm{M}$ & $\mathrm{H}$ & $\mathrm{H}$ & VL & $\mathrm{MH}$ \\
\hline
\end{tabular}




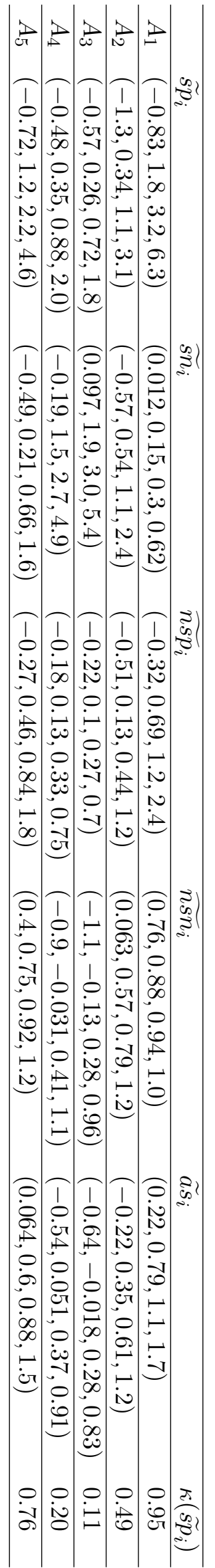

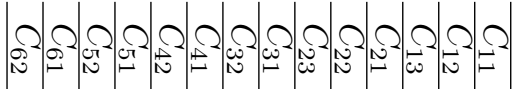

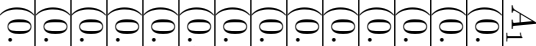

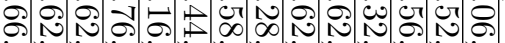
0000000000000 a 선 - 000000000

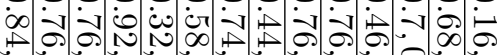
$\therefore 0$ : $00000<00$

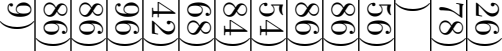
ب

- olo olo olo a ocon

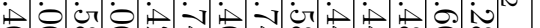

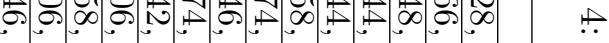
0000000000000 急 - 0.000000000 舟 00000000 Nol

西

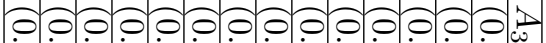
计 -0 0 0 0 0 0 0 0

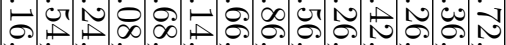
- o o o o o 0000000 क

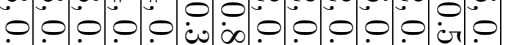

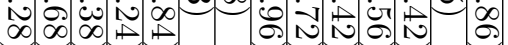

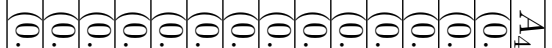

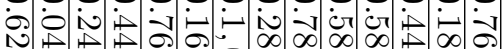
- 0 0 0 0 00000

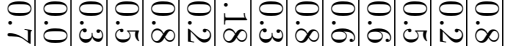

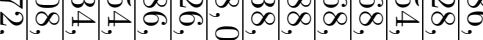

- 0 0 0 il o 0.000

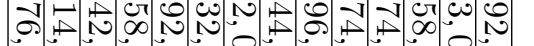

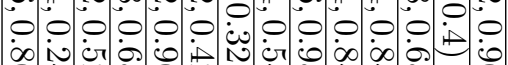

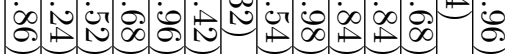

ฉั้

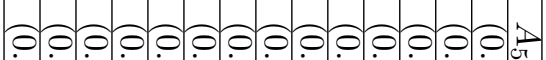

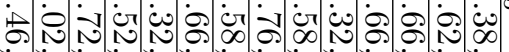

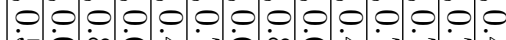
did 000000000

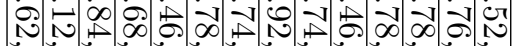
- o o o o o o o o o 0.0

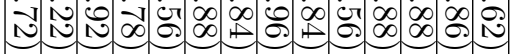
记

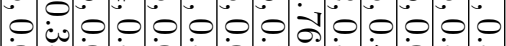

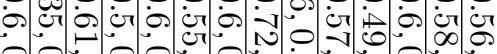
- 당 0

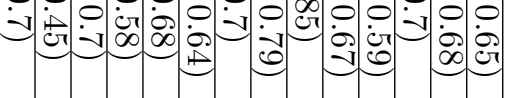




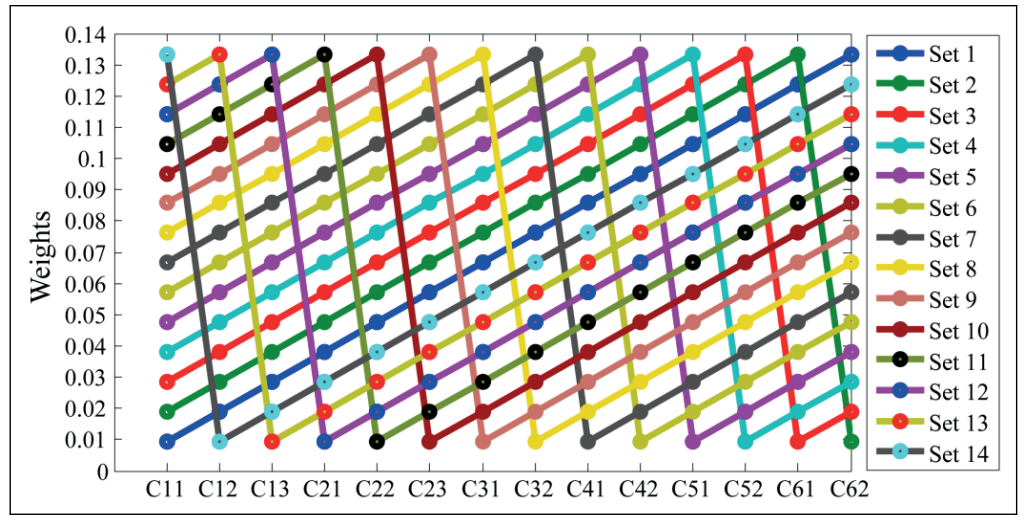

Figure 3: The simulated weights for sensitivity analysis

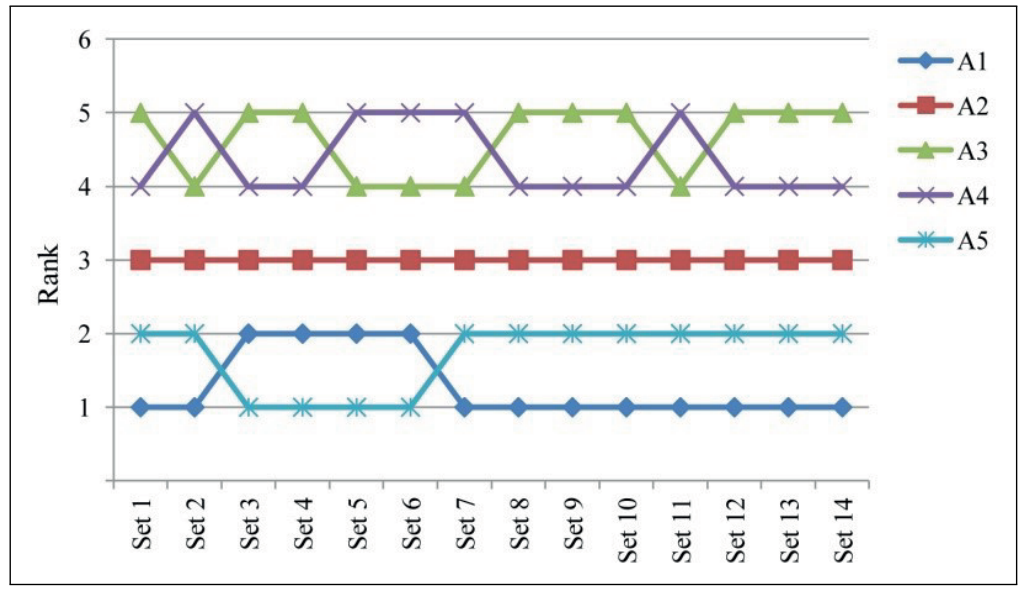

Figure 4: The rank of alternatives in different sets

weights. For example, the best alternative is $A_{1}$ or $A_{5}$ and the worst alternative is $A_{3}$ or $A_{4}$ in all sets. To show the changes clearly, the shapes of fuzzy appraisal scores are represented in Figure 5. The smooth changes which can be seen in this figure show that the results of the proposed method are stable when the weights of criteria (sub-criteria) are varied. Therefore, we can say that the proposed fuzzy method is efficient for ranking alternatives in an MCDM problem.

\section{Conclusion}

Multi-criteria decision-making is an important sub-discipline of operations research that considers multiple criteria in the decision-making process. Due to uncertainty of data in this process, the problems cannot precisely be modeled by crisp values. Fuzzy MCDM methods are efficient tools to deal with the uncertain decision-making problems and have been used widely because of their ability to solve a broad range of problems in different application fields. These methods can be used in the decision-making software to make some efficient decision support systems [1], [11], [32]. The method presented in this paper will be a basis for development of a novel fuzzy decision-making software or decision support systems, which supports fuzzy data and allows to solve different problems. In this research, the EDAS method, which is an efficient MCDM method, has been developed to handle fuzzy multi-criteria decision-making problems. Linguistic terms determined by trapezoidal fuzzy numbers have been utilized for extending this method. We have used this method in a case study of supplier selection to illustrate the proce- 


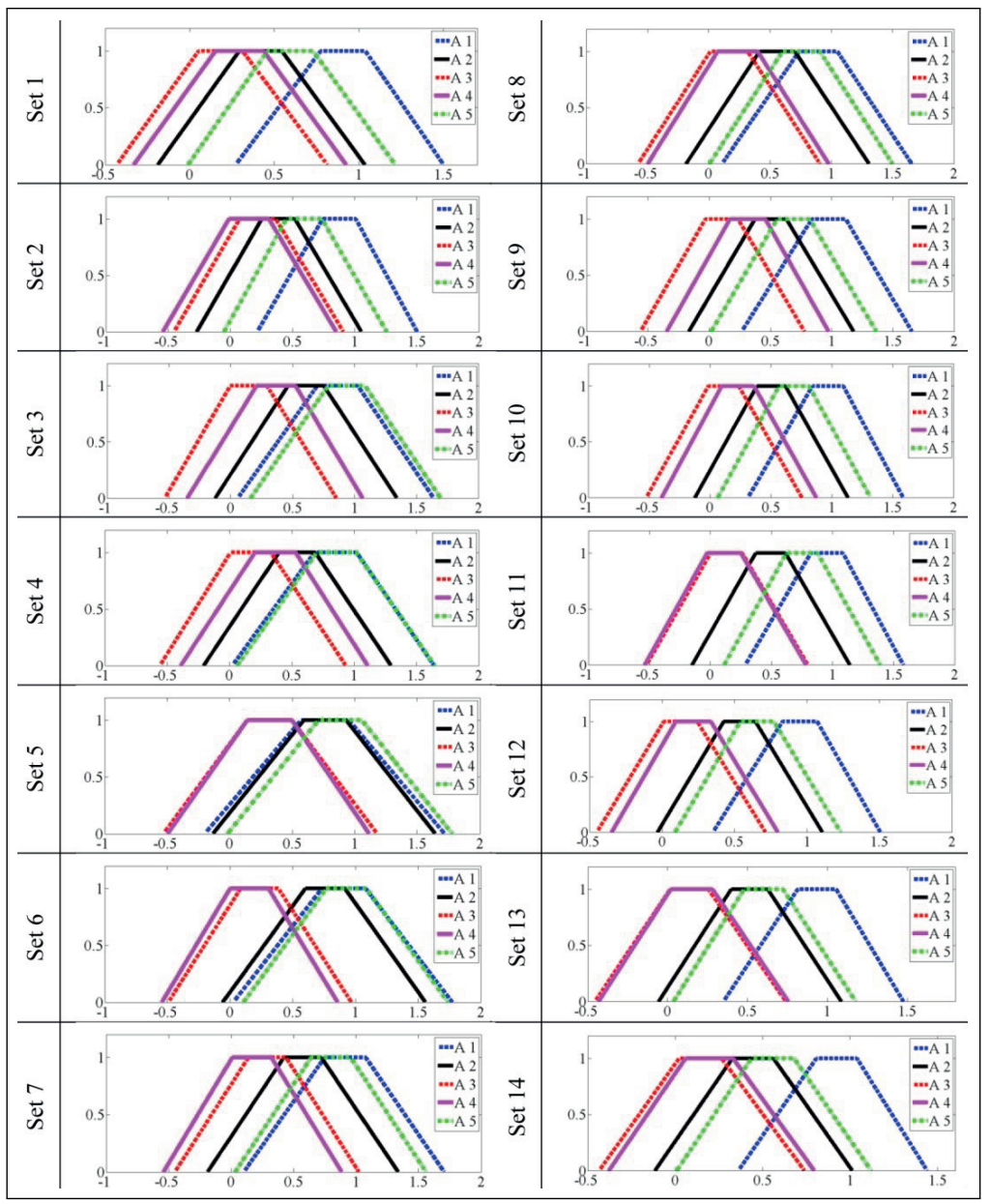

Figure 5: The fuzzy appraisal scores of alternatives in each sets of criteria weight

dure of the proposed method and show the applicability of it in the real-world MCDM problems. A sensitivity analysis has been performed to represent the stability of the results. We have simulated 14 sets of criteria weights to perform this analysis. In each of these sets, one criterion (sub-criterion) has the highest and one criterion (sub-criterion) has the lowest weight. The result of the sensitivity analysis shows the stability of the fuzzy EDAS method in solving multi-criteria decision-making problems.

\section{Bibliography}

[1] Adeli (Ed.), H. (1988); Expert Systems in Construction and Structural Engineering, Chapman and Hall, New York.

[2] Baležentis, A.; Baležentis T. (2011); An innovative multi-criteria supplier selection based on two-tuple MULTIMOORA and hybrid data, Economic Computation and Economic Cybernetics Studies and Research, 2: 1-20.

[3] Baležentis, T. et al (2014); MULTIMOORA-IFN: A MCDM method based on intuitionistic fuzzy number for performance management, Economic Computation and Economic Cybernetics Studies and Research, 48(4): 85-102. 
[4] Bogdanovic, D.; Miletic S. (2014); Personnel evaluation and selection by multicriteria decision making method, Economic Computation and Economic Cybernetics Studies and Research, 48(3): 179-196.

[5] Brauers, W.K.M. et al (2011); Multimoora for the EU member states updated with fuzzy number theory, Technological and Economic Development of Economy, 17(2): 259-290.

[6] Cagri Tolga, A. et al (2013); A fuzzy multi-criteria decision analysis approach for retail location selection, International Journal of Information Technology and Decision Making,12(4): 729-755.

[7] Chakraborty, S. et al (2015); Applications of WASPAS method as a multi-criteria decisionmaking tool, Economic Computation and Economic Cybernetics Studies and Research, 49(1): $1-17$.

[8] Chen, S.J.; Hwang C.L. (1992); Fuzzy Multiple Attribute Decision Making: Methods and Applications, Berlin Heidelberg: Springer.

[9] Dadelo, S. et al (2014); Algorithm of maximizing the set of common solutions for several MCDM problems and it's application for security personnel scheduling, International Journal of Computers Communications \& Control, 9(2): 151-159.

[10] Elsayed, A. et al (2015); Fuzzy linear physical programming for multiple criteria decisionmaking under uncertainty, International Journal of Computers Communications \& Control, 11(1): 26-38.

[11] Filip, F.G. et al (2014); DSS in numbers, Technological and Economic Development of Economy, 20(1): 154-164.

[12] Ho, W. et al (2010); Multi-criteria decision making approaches for supplier evaluation and selection: A literature review, European Journal of Operational Research, 202(1): 16-24.

[13] Keshavarz Ghorabaee, M. et al (2015); Genetic algorithm for solving bi-objective redundancy allocation problem with k-out-of-n subsystems, Applied Mathematical Modelling, 39(20): 6396-6409.

[14] Keshavarz Ghorabaee, M.(2016); Developing an MCDM method for robot selection with interval type-2 fuzzy sets, Robotics and Computer-Integrated Manufacturing, 37: 221-232.

[15] Keshavarz Ghorabaee, M. et al (2014); Multiple criteria group decision-making for supplier selection based on COPRAS method with interval type-2 fuzzy sets, The International Journal of Advanced Manufacturing Technology, 75(5-8): 1115-1130.

[16] Kar, A.K. (2015); A hybrid group decision support system for supplier selection using analytic hierarchy process, fuzzy set theory and neural network, Journal of Computational Science, 6: 23-33.

[17] Keshavarz Ghorabaee, M. et al (2015); Multi-criteria inventory classification using a new method of evaluation based on distance from average solution (EDAS), Informatica, 26(3): 435-451.

[18] Keshavarz Ghorabaee, M. et al (2015); Multi-criteria project selection using an extended VIKOR method with interval type-2 fuzzy sets, International Journal of Information Technology 85 Decision Making, 14(5): 993-1016. 
[19] Kosareva, N. et al (2015); Personnel ranking and selection problem solution by application of KEMIRA method, International Journal of Computers Communications $\&$ Control, 11(1): 51-66.

[20] Nieto-Morote, A.; Ruz-Vila F. (2011); A fuzzy AHP multi-criteria decision-making approach applied to combined cooling, heating, and power production systems, International Journal of Information Technology and Decision Making, 10(3): 497-517.

[21] Ölçer, A.Y.; Odabaşi A.Y. (2005); A new fuzzy multiple attributive group decision making methodology and its application to propulsion/manoeuvring system selection problem, European Journal of Operational Research, 166(1): 93-114.

[22] Pitchipoo, P. et al (2013); Fuzzy hybrid decision model for supplier evaluation and selection, International Journal of Production Research, 51(13): 3903-3919.

[23] Sedaghat, M. (2013); A productivity improvement evaluation model by integrating AHP, TOPSIS and VIKOR methods under fuzzy environment (case study: State-owned, partially private and private banks in Iran), Economic Computation and Economic Cybernetics Studies and Research, 47(1): 235-258.

[24] Stanujkic, D. (2015); Extension of the ARAS method for decision-making problems with interval-valued triangular fuzzy numbers, Informatica, 26(2): 335-355.

[25] Stanujkic, D.; Zavadskas E.K. (2015); A modified weighted sum method based on the decision-maker's preferred levels of performances, Studies in Informatics and Control, 24(4): 461-470.

[26] Turskis, Z. et al (2015); A hybrid model based on fuzzy AHP and fuzzy WASPAS for construction site selection, International Journal of Computers Communications $\&$ Control, 10(6): 113-128.

[27] Turskis, Z.; Zavadskas E.K. (2010); A new fuzzy additive ratio assessment method (ARASF). Case study: The analysis of fuzzy multiple criteria in order to select the logistic centers location, Transport, 25(4): 423-432.

[28] Wan, S.; Dong J. (2014); Multi-attribute group decision making with trapezoidal intuitionistic fuzzy numbers and application to stock selection, Informatica, 25(4): 663-697.

[29] Wang, Y.J.; Lee H.S. (2007); Generalizing TOPSIS for fuzzy multiple-criteria group decisionmaking, Computers 83 Mathematics with Applications, 53(11): 1762-1772.

[30] Yücenur, G.N. et al (2011); Supplier selection problem in global supply chains by AHP and ANP approaches under fuzzy environment, The International Journal of Advanced Manufacturing Technology, 56(5-8): 823-833.

[31] Zadeh, L.A.(1965); Fuzzy sets, Information and Control, 8(3): 338-353.

[32] Zavadskas, E.K. et al (1995); Expert Systems in Construction Industry. Trends, Potential $\mathcal{G}^{3}$ Applications, Technika, Vilnius.

[33] Zavadskas, E.K. et al (2013); Multi-criteria assessment model of technologies, Studies in Informatics and Control, 22(4): 249-258. 
[34] Zavadskas, E.K. et al (2015); Selecting a contractor by using a novel method for multiple attribute analysis: weighted aggregated sum product assessment with grey values (WASPASG), Studies in Informatics and Control, 24(2): 141-150.

[35] Zavadskas, E.K. et al (2009); Multi-attribute decision-making model by applying grey numbers, Informatica, 20(2): 305-320.

[36] Zimmermann, H.J. (2010); Fuzzy set theory, Wiley Interdisciplinary Reviews: Computational Statistics, 2(3): 317-332. 